In Mr. Karl Hagedorn's "Spanish Fishing Boats" (702) we have a study of the captivating curves of sailing craft which it is now so urgent to record.

Sir John Lavery's impressive portrait "Grey 0 wl" (553) is of special interest to the scientific world. This man, a Red Indian, by a self-denying life in the company of beavers, has carried our knowledge of an animal species to a point which it is only possible to attain when intellect is reinforced by loving-kindness.

\section{VAUGHAN CORNISH.}

Among the portraits of men of science are Catherine Dodgson's chalk drawing, "Sir Thomas Barlow, Bt., M.D., F.R.S." (1236) ; a white metal bust "Dr. Alexander Scott, F.R.S." (1518) by Sir W. Reynolds-Stephens ; a charcoal drawing of Sir Almroth Wright, K.B.E., C.B., M.D., F.R.S.
(1212) by Francis Dodd and also a bronze bust of Sir Almroth (1503) by Donald Gilbert; oil paintings of "Dr. J. Vargas Eyre, Ph.D., M.A." (375) by Algernon Talmage, and "A. E. Morgan, Esq., M.A., Principal and Vice-Chancellor of McGill University, Montreal, formerly Principal of University College, Hull" (409) by Frederick W. Elwell ; miniatures of "Emeritus Professor R. W. Reid, M.D., LL.D., F.R.C.S.”, emeritus regius professor of anatomy, University of Aberdeen (1055) by Isabella E. Reid, and "Bernard Dyer, Esq., D.Sc." (1133) by Inés Johnson; mezzotints of "Thomas Telford, after Sir Henry Raeburn, R.A." (1311) and "The Viscount Wakefield of Hythe, C.B.E." (1335) by H. Macbeth-Raeburn.

In addition, mention may be made of two architectural drawings by Charles Holden, "London University: Bird's-eye View from South-West" (1368) and "London University" (1451).

\title{
Hofmann and his Influence on Chemistry in Great Britain
}

IN his Hofmann Memorial Lecture, delivered at the Imperial College of Science and Technology on May 4, Prof. G. T. Morgan dealt with A. W. von Hofmann's career as chemist and teacher, and vividly recalled the extraordinary influence which he had on contemporary chemistry and chemical technology in Great Britain.

The main facts of Hofmann's life and work are well known through the original lectures delivered before the Chemical Society in 1893 by Lord Playfair, Sir Frederick Abel, Sir William Perkin and Prof. H. E. Armstrong. Hofmann came to England from Bonn in 1845 as a young man of twenty-seven, and spent the best years of his life in this country. Most chemical discoveries had until that time been the work of brilliant individuals, and it was left for Hofmann and for Graham to found the first schools for the training of chemical investigators. The times were peculiarly propitious for the new developments : Liebig's tour of the country in 1842 had awakened a general interest in chemistry, and, under the leadership of the Prince Consort, Sir James Clerk and Playfair, the Royal School of Mines and Royal College of Chemistry were founded. Hofmann became the first director of the latter, which rapidly developed as a centre for both instruction and original research. The early account books of the College show that chemistry became a popular and even fashionable study, owing no doubt to Hofmann's close associations with the Royal family. When he left England, twenty years later, to use Prof. Morgan's words, "Hofmann had established a school of research in organic chemistry such as had never existed before in this country."

Organic chemistry was then beginning the rapid development which was one of the main features of the science of the second half of the nineteenth century, and Hofmann was one of the first great chemists to specialise in this particular branch. His name is particularly associated with that of aniline, the compound which he described as his first love. In 1843, he investigated the "cyanol" of coal tar and suggested that this was identical with the bases "aniline" and "crystallin" prepared by the degradation of indigo and with the "benzidam" obtained by reducing nitrobenzene, a view which was afterwards shown to be correct. In later investigations he dealt with a wide range of derivatives of aniline, including the chloranilines and the phenyl carbamides. The early experiments were greatly hampered by scarcity of material; aniline was made from indigo and "the production of a few ounces was a proud achievement".

Hofmann was greatly attracted by Wurtz's contemporary discovery of monomethylamine and monoethylamine. This led him to investigate whether the remaining two hydrogen atoms attached to nitrogen in aniline and the alkylamines could be substituted by alkyl radicals without affecting the general nature of the bases. This led to the discovery of the alkyl anilines and of the quaternary ammonium compounds. Hofmann at once correctly interpreted the nature of these substances and their theoretical significance. Prof. 
Morgan pointed out that the work foreshadowed the discovery that the four radicals surrounding the nitrogen atom in the tetra-alkyl ammonium salts are in equivalent positions. Another example of Hofmann's acumen in theoretical matters was shown in his work with Cahours on the corresponding compounds derived from phosphorus, in which the analogies between nitrogen, phosphorus, arsenic and antimony were clearly recognised. This was some twelve years before the development of the periodic law by Mendeléeff and Lothar Meyer. For the preparation of the trialkyl phosphines, Hofmann and Cahours used the corresponding zine alkyls, which had recently been discovered by Frankland. With these classical investigations, the name of Hofmann will always be associated.

Prof. Morgan's lecture recalled many less known facts, for example, that Hofmann was responsible for the discovery of allyl alcohol, the first unsaturated alcohol (with Cahours), and of formaldehyde.

A brilliant group of pupils and assistants worked under Hofmann's direction during the prosecution of these researches. They included Abel, de la Rue, Merck, Crookes, Divers, Clowes and Newlands and the founders of the synthetic dyestuff industry in Perkin, Nicholson, Mansfield, Griess, Martius, Medlock and Greville Williams. The record of these men in science and technology is a testimony to Hofmann's extraordinary power of kindling enthusiasm among those with whom he came into contact.
Hofmann was the midwife at the birth of the organic dyestuff and fine-chemical industry. His pupils founded the first factories, and his researches on the aromatic bases acted as the scientific foundation of the technical processes. Prof. Morgan gave a very interesting picture of the influence which Hofmann and his school had on the early growth of the industry. Perkin's original discovery of mauve was made at a time when he was Hofmann's assistant, and the connexion was maintained by Mansfield's collaboration with the firm of Read Holliday of Huddersfield, and with the scientific investigations of Hofmann himself and of Nicholson on the rosaniline bases. The name of Perkin is deservedly honoured. Nicholson and Mansfield have perhaps not received the recognition which their pioneer work merits.

It is well known that Perkin's second great success was the synthesis from anthracene of alizarine, the natural colouring matter of the madder root, used in the production of 'Turkey Red'. The first research assigned to Perkin by Hofmann was a study of "paranaphthalene", as anthracene was then called. The experience gained by Perkin, then sixteen years of age, must have been invaluable to him later.

Although the heroic period of the colour-making industry in Great Britain has passed, it is satisfactory to realise that it has completely recovered from its pre-War decline, and that, in Prof. Morgan's opinion, four of the six outstanding dis. coveries in tinctorial chemistry of recent times have been made by British chemists.

\section{Obit uary}

Sir Archibald Garrod, K.C.M.G., F.R.S. A RCHIBALD GARROD, who died at the age of A seventy-eight years on March 28 last, was a physician to whom the chemical aspects of pathology and clinical medicine made a special appeal. His father, Sir Alfred Garrod, M.D., F.R.S., had the same tastes. He was deeply interested in chemistry as a science, and though professional calls left little leisure for these pursuits, delighted in laboratory experiments. As many will remember, Alfred Garrod was the first to give a convincing demonstration of the presence of uric acid in the blood of gouty patients. This was in 1848 , and his son was able to claim with pride that it involved the first biochemical observation of the kind made on the living human body. These paternal interests may have awakened those of the son, though in the latter love of chemistry seems to have been innate.

Archibald Garrod went from Marlborough to Christ Church, Oxford, and took a first class in natural science in 1884. For his medical training he joined St. Bartholomew's Hospital and became distinguished as a student. He was marked out for the visiting staff, but promotion at Bart's. was at that time very slow, and it was not until 1903 that he became assistant physician. In the intervening years, however, he held other clinical posts, of which the most important was that of honorary physician to the Great Ormond Street Hospital for Sick Children. It was during these years that he found leisure for personal research.

Garrod was led to take a special interest in urinary pigments, and between 1892 and the end of the century he published a series of papers dealing with these. Each of the best known among the excretory pigments received his attention in turn: hæmatoporphyrin, urochrome, uroerythrin and urobilin. His publications on these were mainly descriptive, and the spectroscope played a chiof part in the studies; but all the observations were 